\title{
Analisis Kebutuhan Fasilitas Penyeberangan Orang
}

(Studi Kasus : Jalan Pandanaran, Jalan Mt Haryono, Jalan Teuku Umar, Semarang)

\author{
Pandu Astha Lazuardi ${ }^{1}$, Rizky Alfiandhi Prasetya ${ }^{2}$, \\ Djoko Setijowarno ${ }^{3}$, Rudatin Ruktiningsih ${ }^{4}$ \\ email: ${ }^{1}$ panduastha69@gmail.com, ${ }^{2}$ rizkyalfiandhi@gmail.com
}

Program Studi Teknik Sipil, Fakultas Teknik, Unika Soegijapranata, Semarang, Universitas Katolik Soegijapranata; Jl. Pawiyatan Luhur IV/1 Bendan Dhuwur Semarang 50234, 024-8441555

\begin{abstract}
Abstrak
Bersamaan dengan kemajuan dan perkembangan populasi pada Kota besar volume kendaraan dan pejalan kaki semakin meningkat. Hal ini akan mengakibatkan konflik antara volume kendaraan yang melintas dengan pejalan kaki yang menyeberang. Permasalahan yang terjadi yaitu konflik antara penyeberang jalan dengan kendaraan bermotor yang memungkinkan terjadinya kecelakaan. Untuk menghindari terjadinya kecelakaan maka diperlukan fasilitas penyeberangan orang. Penelitian ini bertujuan untuk menganalisis akan kebutuhan fasilitas penyeberangan bagi pejalan kaki dan memberikan rekomendasi jenis fasilitas penyeberangan orang yang tepat. Pengumpulan data dilakukan dengan cara survey langsung di titik lokasi yang telah ditentukan yang diamati selama tiga hari pada jam - jam sibuk. Data- data yang diambil berupa volume kendaraan, volume pejalan kaki, dan geometri jalan. Data yang didapatkan digunakan untuk mendapatkan nilai PV2. Nilai tersebut akan digunakan untuk menentukan jenis fasilitas penyeberangan orang yang sesuai dengan titik lokasi yang ditentukan. Hasil perhitungan PV2 untuk empat titik lokasi yang diamati didapatkan tiga lokasi yang layak untuk direncanakan pembangunan fasilitas penyeberangan orang, yaitu pada ruas jalan Pandanaran di titik lokasi toko peralatan AGUSTA berupa pelican crossing (lampu swakelola) dengan nilai PV2 139.332.136,5. Ruas jalan MT Haryono di titik lokasi Java Mall berupa pelican crossing (lampu swakelola) dengan lapak tunggu yang nilai PV2 223.380.673,3. Ruas jalan Teuku Umar di titik lokasi Pasar Jatingaleh berupa penyeberangan tidak sebidang dengan nilai PV2 1.087.398.217. Satu lokasi tidak memerlukan fasilitas penyeberangan orang, yaitu pada ruas jalan Teuku Umar depan SMK Antonius tidak diperlukan fasilitas penyeberangan orang.
\end{abstract}

Kata kunci : Volume Kendaraan, Volume Penyeberangan, Fasilitas Penyeberangan, Pelican Crossing

Abstract
Along with the progress and development of the population in the City, large volumes of vehicles and
pedestrians are increasing. This will result in a conflict between the volume of vehicles passing and
pedestrians crossing. The problem that occurs is the conflict between road crossers and motorized
vehicles that allows accidents to occur. To avoid accidents, crossing facilities are needed. This study
aims to analyze the need for pedestrian crossing facilities and provide recommendations on the type
of crossing facilities for the right person. Data collection is done by direct survey at a predetermined
location point observed for three days during rush hour. The data taken is in the form of vehicle
volume, pedestrian volume, and road geometry. The data obtained is used to get the PV2 value. This
value will be used to determine the type of crossing facility for the person that matches the specified

G-SMART Jurnal Teknik Sipil Unika Soegijapranata Semarang | ISSN : 2620-5297 (online)

Volume 4 | Nomor 1 | Juni 2020 
location point. The results of PV2 calculations for the four location points observed obtained three feasible locations for the planned construction of crossing facilities, namely on the Pandanaran road section at the location point of AGUSTA equipment store in the form of pelican crossing (lamp swakelola) with a PV2 value of 139,332,136.5. The MT Haryono road at the Java Mall location is in the form of pelican crossing (swakelola lamp) with a waiting stall which has a value of PV2 223,388,673.3. The Teuku Umar road section at the Jatingaleh Market location is in the form of a non-plot crossing with a value of PV2 1,087,398,217. One location does not require crossing facilities for people, that is, on the Teuku Umar road in front of the Antonius Vocational School, no crossing facilities are needed.

Keywords: Vehicle Volume, Crossing Volume, Crossing Facilities, Pelican Crossing

\section{PENDAHULUAN}

Kota Semarang merupakan salah satu kota besar yang merupakan ibukota dari provinsi Jawa Tengah. Bersamaan dengan kemajuan dan perkembangan populasi pada kota besar mengakibatkan semakin banyaknya kendaraan dan pejalan kaki yang lalu lalang untuk menjalankan aktivitasnya. Masalah ini akan menyebabkan konflik antara volume kendaraan yang melintas dengan volume pejalan kaki yang menyeberang. Volume kendaraaan dan pejalan kaki yang tinggi mengidentifikasikan bahwa lokasi tersebut merupakan jalan utama. Karena tingginya volume pengguna jalan yang ingin menyeberang dan volume kendaraan yang melintas akan mempengaruhi lalu lintas di jalan raya dan kemungkinan akan terjadi kecelakaan. Para pejalan kaki akan menerima dampak dari masalah tersebut karena sebagian besar korban kecelakaan merupakan pejalan kaki sama halnya dengan pengguna kendaraan akan mengalami kerugian materi yang cukup besar. Karena adanya permasalahan yang timbul tersebut muculah keinginan bagaimana cara mengatasi permasalahan tersebut. Bentuk dan kenyamanan pedestrian dan kepadatan lalu lintas kendaraan bermotor di jalan raya sangat mempengaruhi untuk menentukan jenis fasilitas penyeberangan pejalan kaki.
Analisis kebutuhan fasilitas penyeberangan orang dilakukan di Jalan Pandanaran, Jalan MT Haryono, dan Jalan Teuku Umar. Alasan penelitian ini dilakukan pada ruas jalan tersebut karena banyakya masyarakat yang melakukan kegiatan pada ruas jalan tersebut. Pada ruas jalan Pandanaran titik lokasi penelitian difokuskan pada Toko Peralatan Kantor Agusta, pada ruas jalan MT Haryono penelitian difokuskan pada pusat perbelanjaan Java Mall, dan untuk ruas jalan Teuku Umar terdapat dua lokasi penelitian, yang pertama di depan SMK Antonius dan yang kedua di depan Pasar Jatingaleh. Oleh karena itu, untuk meminimalkan hal-hal yang tidak diinginkan antara penggunan jalan dengan pejalan kaki, untuk memudahkan dan dapat memberikan kenyamanan pada pejalan kaki diperlukan analisis mengenai kebutuhan fasilitas penyeberangan jalan dengan berpedoman pada Kementrian Pekerjaan Umum dan perumahan Rakyat 2018 mengenai Perencanaan Teknis Fasilitas Pejalan kaki. Kendaraan yang melintas pada suatu ruas jalan terdiri dari berbagai tipe kendaraan, oleh karena itu untuk mengatasi perbedaan ruang yang digunakan oleh suatu kendaraan diperlukan nilai konversi yang lebih dikenal sebagai satuan mobil penumpang (SMP). Nilai konversi tersebut telah diatur 
dalam Manual Kapasitas Jalan Indonesia (MKJI) 1997.

\section{TINJAUAN PUSTAKA}

Undang-undang No.22 tahun 2009 dituliskan bahwa lalu lintas yaitu sebagai gerak kendaraan dan orang di ruang lalu lintas. Ruang lalu lintas sendiri memiliki arti sebagai prasarana berupa jalan dan fasilitas yang mendukung yang ditujukan untuk gerak pindah kendaraan, batang dan juga manusia. Dari pengertian yang telah dijelaskan dapat disimpulkan bahwa lalu lintas merupakan kegiatan berpindahnya kendaraan bermotor, manusia, atau barang dengan menggunakan jalan raya sebagai medianya.

Menurut Peraturan Pemerintah Republik Indonesia Nomor 44 Tahun 1993 Tentang Kendaraan dan Pengemudi dituliskan bahwa kendaraan bermotor dikelompokkan dalam beberapa jenis, yaitu:

a. Sepeda motor merupakan kendaraan bermotor beroda dua, atau tiga tanpa rumah-rumah baik dengan atau tanpa kereta samping.

b. Mobil penumpang adalah setiap kendaraan bermotor yang dilengkapi sebanyak-banyaknya 8 tempat duduk tidak termasuk tempat duduk pengemudi, baik dengan mauoun tanpa perlengkapan pengangkutan bagasi.

c. Mobil bus adalah setiap kendaraan bermotor yang dilengkapi lebih dari 8 tempat duduk tidak termasuk tempat duduk pengemudi, baik dengan maupun tanpa perlengkapan pengangkutan bagasi.

d. Mobil barang yaitu setiap kendaraan bermotor selain dari yang termasuk dalam sepeda motor, mobil penumpang, dan mobil bus.

e. Kendaraan khusus adalah kendaraan bermotor selain daripada kendaraan bermotor untuk penumpang dan kendaraan bermotor untuk barang, yang penggunaanya untuk keperluan khusus atau mengangkut barang-barang khusus.

Berdasarakan UU RI No. 38 Tahun 2004 tentang jalan, pengertian jalan yaitu:

a. Jalan adalah prasarana transportasi darat yang meliputi segala bagian jalan, termasuk bangunan pelengkap dan perlengkapannya yang diperuntukkan bagi lalu lintas, yang berada pada permukaan tanah, di bawah permukaan tanah dan/atau air, serta diatas permukaan air, kecuali jalan kereta api, jalan lori, dan jalan kabel.

b. Jalan umum adalah jalan yang diperuntukkan bagi lalu lintas umun

c. Jalan khusus adalah jalan yang dibangun oleh instansi, badan usaha, perseorangan, atau kelompok masyarakat untuk kepentingan sendiri.

d. Jalan tol adalah jalan umum yang merupakan bagian sistem jaringan jalan dan sebagai jalan nasional yang penggunaanya diwajibkan membayar biaya tol.

Menurut UU No. 22 tahun 2009 tentang Angkutan Jalan dan Lalu Lintas dalam pasal 1, pengertian pejalan kaki adalah setiap orang yang berjalan di Ruang Lalu Lintas Jalan. Sedangkan yang dimaksud pengguna jalan adalah orang yang menggunakan jalan untuk berlalu lintas. Pejalan kaki yaitu orang yang sedang melakukan kegiatan berjalan kaki termasuk salah satu unsur pengguna jalan. (Keputusan Direktur Jendral Perhubungan Darat : SK.43/AJ 007/DRDJ/97). Pada saat berjalan pejalan kaki harus menggunakan fasilitas yang telah disediakan yaitu trotoar yang letaknya di bagian paling kiri pada jalan raya. Pejalan kaki yang memiliki fisik dengan kebutuhan khusus dibagi menjadi 3, yaitu: 
a. Penyeberang difabel atau cacat fisik merupakan pengguna jalan yang memiliki keterbatasan fisik atau kekurangan fisik sehingga membutuhkan fasilitas khusus.

b. Penyeberangan anak - anak merupakan pengguna jalan dengan rentang usia 0 12 tahun. Kecelakaan pada golongan ini biasanya dipengaruhi karena area lalu lintas yang tidak terkontrol, kebiasaan anak kecil yang suka berlari, dan pada saat penglihataan sopir yan terhalang

c. Penyeberang usia lanjut merupakan penyeberang yang memiliki fisik yang lemah dan membutuhkan waktu lama untuk menyeberang

Salah satu bentuk manajemen pejalan kaki yaitu menyediakan fasilitas untuk pejalan kaki. Dilihat dari letak bidangnya, fasilitas penyeberangan pejalan kaki dapat dibedakan menjadi dua jenis yaitu (Kementerian Pekerjaan Umum dan Perumahan Umum, 2018) :

a. Penyeberangan sebidang

Kriteria pemilihan penyeberangan sebidang berdasarkan pada rumus $\left(\mathrm{PV}^{2}\right)$, dimana $\mathrm{P}$ merupakan arus pejalan kaki yang menyeberang ruas jalan sepanjang 100 meter tiap jamnya (pejalan kaki/jam) dan $\mathrm{V}$ yaitu arus kendaraan yang melintas tiap jam dalam dua arah (kendaraan/jam). Nilai $\mathrm{P}$ dan $\mathrm{V}$ didapatkan dari rata-rata pejalan kaki dan kendaraan pada jam sibuk. Penyeberangan sebidang dapat diaplikasikan pada persimpangan maupun ruas jalan, berikut merupakan jenis penyeberangan sebidang yaitu:

1. Penyeberangan Zebra Cross

2. Penyeberangan Pelican Cross (lampu swakelola)

3. Pedestrian Platform

b. Penyeberangan tidak sebidang

Penyeberangan tidak sebidang dapat digunakan apabila fasilitas penyeberangan yang sudah ada mengganggu arus lalu lintas yang ada. Terjadi banyak kecelakaan yang melibatkan antara pejalan kaki dengan kendaraan bermotor. Penyeberangan tidak sebidang digunakan pada ruas jalan yang memiliki kecepatan rencana $>70 \mathrm{~km} / \mathrm{jam}$. Dan juga pada lokasi tertentu yang mengharuskan penyeberangan jalan menggunakan fasilitas penyeberangan jalan tidak sebidang. Penyeberangan tidak sebidang dibedakan menjadi:

1. Jembatan Penyeberangan Orang

2. Terowongan Underpass

Untuk menentukan jenis fasilitas penyeberangan orang metode yang digunakan adalah mengkonversi

Kendaraan yang melintas pada suatu ruas jalan dengan kendaraan mobil penumpang, untuk mengkonversikan satuan mobil penumpang (smp) digunakan ekvalensi mobil penumpang (emp) atau variabel pengali beberapa jenis kendaraan menjadi satu satuan yang sama yaitu (smp). Pada jalan perkotaan fungsi, kondisi jalan dan juga jumlah kendaraan yang melintas dan mempengaruhi faktor pengali pada satu satuan periode waktu (jam). Berikut merupakan nilai ekivalensi pada jalan perkotaan.

Tabel 1. Nilai Ekivalensi Mobil Penumpang (emp) untuk Jalan perkotaan Tak-Terbagi

\begin{tabular}{|c|c|c|c|c|}
\hline \multirow{2}{*}{$\begin{array}{c}\text { Tipe } \\
\text { jalan: }\end{array}$} & \multirow{2}{*}{$\begin{array}{c}\text { Arus } \\
\text { lalu-lintas } \\
\text { Jalan } \\
\text { total dua } \\
\text { tak } \\
\text { terbagi }\end{array}$} & \multirow{2}{*}{$\begin{array}{c}\text { emph } \\
\text { (kend/jam) }\end{array}$} & $\mathbf{H V}$ & \multicolumn{2}{|c|}{ MC } \\
\cline { 3 - 5 } & & \multicolumn{2}{|c|}{$\begin{array}{c}\text { Lebar jalur } \\
\text { lalu-lintas } \\
(\mathbf{m})\end{array}$} \\
\cline { 3 - 5 } & & \multicolumn{2}{|c|}{$\mathbf{6}$} & $\mathbf{6}$ \\
\hline $\begin{array}{c}\text { Dua } \\
\text { lajur tak } \\
\text { terbagi } \\
\text { (2/2 UD) }\end{array}$ & $0 \geq 1800$ & 1,3 & 0,50 & 0,40 \\
\hline $\begin{array}{c}\text { Empat } \\
\text { lajur tak }\end{array}$ & $0 \geq 3700$ & 1,2 & 0,35 & 0,25 \\
\hline
\end{tabular}




\section{terbagi}

(4/2 UD)

(Sumber : Manual Kapasitas Jalan Indonesia, 1997)

Tabel 2. Nilai Ekivalen Mobil

Penumpang (emp) untuk Jalan perkotaan

Terbagi dan Satu Arah

\begin{tabular}{|c|c|c|c|}
\hline Tipe jalan: & Arah lalu- & \multicolumn{2}{|c|}{ emp } \\
\cline { 3 - 4 } $\begin{array}{c}\text { Jalan satu } \\
\text { arah dan } \\
\text { jalan } \\
\text { terbagi }\end{array}$ & $\begin{array}{c}\text { lintas per } \\
\text { lajur } \\
\text { (kend/jam) }\end{array}$ & HV & MC \\
\hline $\begin{array}{c}\text { Dua lajur } \\
\text { satu arah } \\
\text { (2/1) dan } \\
\text { Empat lajur } \\
\text { terbagi } \\
\text { (4/2D) }\end{array}$ & $0 \geq 1050$ & 1,3 & 0,40 \\
\hline $\begin{array}{c}\text { Tiga lajur } \\
\text { satu arah } \\
\text { (3/1) dan } \\
\text { Enam lajur } \\
\text { terbagi } \\
\text { (6/2D) }\end{array}$ & $0 \geq 1100$ & 1,2 & 0,25 \\
\hline
\end{tabular}

(Sumber : Manual Kapasitas Jalan Indonesia, 1997)

Metode selanjutnya untuk menentukan jenis fasilitas penyeberangan orang dengan menggunakan rumus:

$$
\mathbf{P V}^{2}
$$

Dengan :

$\mathrm{P}=$ Arus pejalan kaki yang menyeberang jalur lalu lintas sepanjang 100 meter (pejalan kaki / jam)

$\mathrm{V}=$ Arus lalu lintas kendaraan dua arah per jam (kendaraan / jam)

Tabel 3. Pemilihan Fasilitas

Penyeberangan tidak Sebidang

\begin{tabular}{|c|c|c|c|}
\hline $\mathbf{P}$ & $\mathbf{V}$ & $\mathbf{P V}^{\mathbf{2}}$ & $\begin{array}{c}\text { Rekomendasi } \\
\text { Awal }\end{array}$ \\
\hline$>1100$ & $>750$ & $\begin{array}{c}>2 \times 10 \\
8\end{array}$ & $\begin{array}{c}\text { Jembatan dan } \\
\text { terowongan }\end{array}$ \\
\hline
\end{tabular}

(Sumber : Kementrian Pekerjaan Umum dan Perumahan Rakyat, 2018)
Tabel 4. Pemilihan Fasilitas

Penyeberangan Sebidang

\begin{tabular}{|c|c|c|c|}
\hline $\mathbf{P}$ & V & $\mathbf{P V}^{2}$ & $\begin{array}{c}\text { Rekomendasi } \\
\text { Awal }\end{array}$ \\
\hline $50-1100$ & $\begin{array}{c}300- \\
500\end{array}$ & $>10^{8}$ & $\begin{array}{c}\text { Zebra Cross } \\
\text { atau pedestrian } \\
\text { platform }\end{array}$ \\
\hline $50-1100$ & $\begin{array}{c}400- \\
750\end{array}$ & $\begin{array}{r}>2 \times \\
10^{8}\end{array}$ & $\begin{array}{c}\text { Zebra cross } \\
\text { dengan lapak } \\
\text { tunggu }\end{array}$ \\
\hline $50-1100$ & $>500$ & \multirow{2}{*}{$>10^{8}$} & \multirow{2}{*}{ Pelikan (p) } \\
\hline$>1100$ & $>300$ & & \\
\hline $50-1100$ & $>750$ & \multirow{2}{*}{$\begin{array}{l}>2 \times \\
10^{8}\end{array}$} & \multirow{2}{*}{$\begin{array}{c}\text { Pelikan dengan } \\
\text { lapak tunggu }\end{array}$} \\
\hline$>1100$ & $>400$ & & \\
\hline
\end{tabular}

(Sumber : Kementrian Pekerjaan Umum dan Perumahan Rakyat, 2018)

Pelican crossing atau lampu swakelola (Pedestrian Linght Control Crossing merupakan jenis penyeberangan zebra cross yang diperlati dengan lampu lalu lintas yang dapat diatur oleh pejalan kaki yang ingin menyeberang dengan cara menekan sebuah tombol yang terpasang pada lampu lalu lintas yang disediakan. Durasi waktu lampu lalu lintas untuk berganti warna pada penyeberangan pelican crossing (lampu swakelola) direncanakan dengan menggunakan sebuah rumus dengan memasukan nilai panjang penyeberangan, lebar penyeberangan, dan juga volume pejalan kaki yang menyeberang sesuai dengan standar Dirjen Perhubungan Darat tahun 1997.

Tabel 2.6 Standar Pengoperasian Penyeberangan Pelican Crossing (lampu swakelola) di Indonesia

\begin{tabular}{|c|c|c|c|}
\hline \multirow{2}{*}{ Periode } & \multicolumn{2}{|c|}{ Lampu Untuk } & \multirow{2}{*}{$\begin{array}{c}\text { Durasi } \\
\text { detik) }\end{array}$} \\
\cline { 2 - 3 } & Kendaraan & $\begin{array}{c}\text { Pejalan } \\
\text { Kaki }\end{array}$ & \\
\hline 1 & Hijau & Merah & $\begin{array}{c}\text { Tidak } \\
\text { ditentukan }\end{array}$ \\
\hline
\end{tabular}




\begin{tabular}{|c|c|c|c|}
\hline 2 & Kuning & Merah & 3 \\
\hline 3 & Merah & Merah & 3 \\
\hline 4 & Merah & Hijau & $\begin{array}{c}\text { Dihitung } \\
\text { mengguna } \\
\text { kan rumus } \\
(2.1)\end{array}$ \\
\hline 5 & Merah & $\begin{array}{c}\text { Hijau } \\
\text { Berkedi }\end{array}$ & 3 \\
\hline 6 & Merah & Merah & 3 \\
\hline
\end{tabular}

(Sumber : Direktorat Jenderal Perhubungan Darat, 1997 dalam Wira Sahari, 2016)

$$
P T=\frac{L}{1,2}+1,7\left(\frac{N}{W-1}\right)
$$

Dengan :

PT = Waktu Hijau Minimum bagi pejalan kaki (detik)

$\mathrm{L} \quad=$ Panjang bidang penyeberangan (meter)

$\mathrm{N} \quad=$ Volume pejalan kaki (pejalan kaki/siklus)

$\mathrm{W}=$ Lebar bidang penyenyeberangan (meter)

\section{METODE PENELITIAN}

Lokasi yang akan dievaluasi dan dijadikan studi kasus yaitu pada Jalan Teuku Umar tepatnya di depan SMK Antonius dan depan Pasar Jatingaleh seperti yang diperlihatkan pada gambar 1 dan gambar 2, Jalan M.T Haryono yang terletak di depan Java Mall seperti yang diperlihatkan pada gambar 3, dan yang terakhir di jalan Pandanaran yang menghubungkan pusat perkantoran dan pembelanjaan seperti yang diperlihatkan pada gambar 4 .

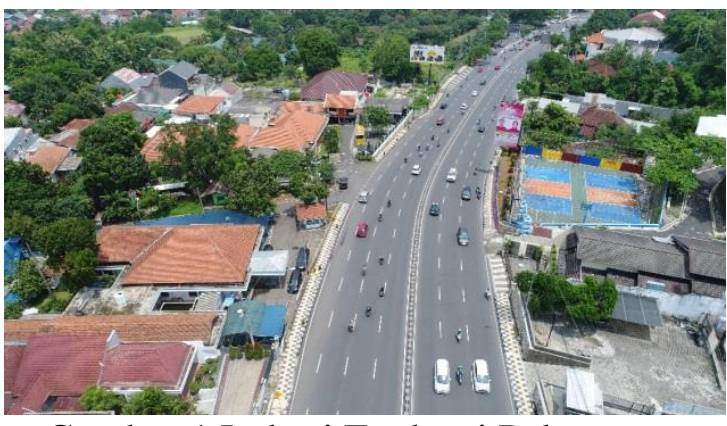

Gambar 1 Lokasi Evaluasi Pelayanan Fasilitas Penyeberangan Jalan Pejalan Kaki Jalan Teuku Umar depan SMK Antonius

(Sumber : Dokumentasi Pribadi diambil pada 26 Januari 2019)

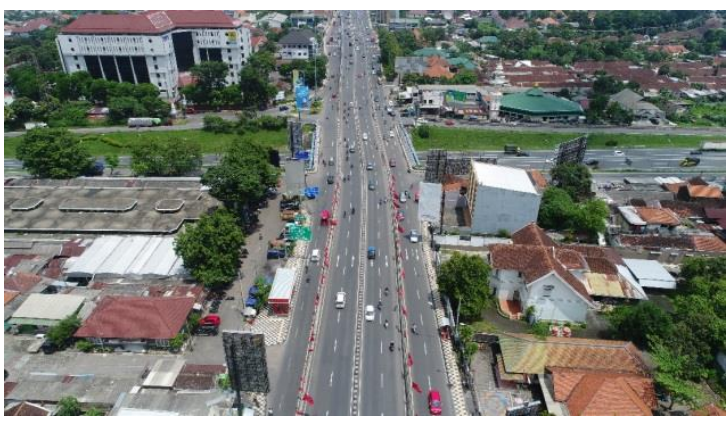

Gambar 3.2 Lokasi Evaluasi Pelayanan

Fasilitas Penyeberangan Jalan Pejalan

Kaki Jalan Teuku Umar depan Pasar Jatingaleh

(Sumber : Dokumentasi Pribadi diambil pada 26 Januari 2019)

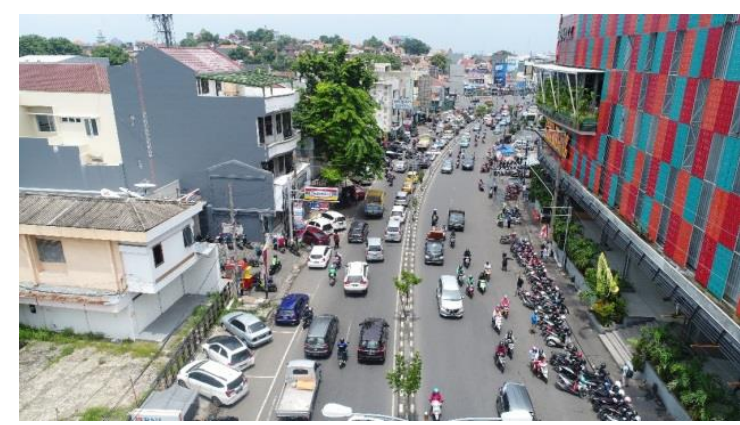

Gambar 3 Lokasi Evaluasi Pelayanan Fasilitas Penyeberangan Jalan Pejalan Kaki Jalan M.T Haryono 
(Sumber : Dokumentasi Pribadi diambil pada 26 Januari 2019)

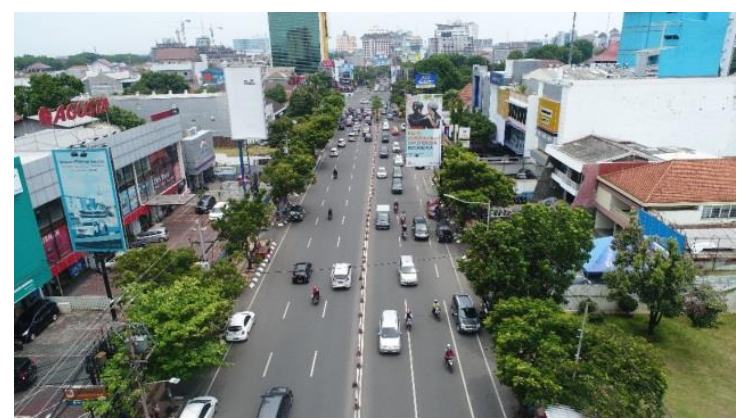

Gambar 3.4 Lokasi Evaluasi Pelayanan

Fasilitas Penyeberangan Jalan Pejalan

Kaki Jalan Pandanaran

(Sumber : Dokumentasi Pribadi diambil pada 26 Januari 2019)

Lokasi-lokasi tersebut dipilih untuk dievaluasi karena jalan yang telah disebutkan merupakan jalanan padat kendaraan dan juga terdapat ejalan kaki yang melintas pada lokasi yang akan dievaluasi tersebut. Karena jalan tersebut merupakan jalan utama yang banyak dilalui oleh kendaraan dan pejalan kaki maka jalan tersebut merupakan lokasi yang pantas untuk menjadi bahan evaluasi mengenai fasilitas penyeberangan jalan untuk pejalan kaki.

Pada penelitian ini data yang dibutuhkan merupakan data primer. Data primer merupakan data penting yang didapatkan langsung oleh pelaku kegiatan. Data primer yang diperlukan yaitu volume kendaraan yang melintas seperti sepeda motor, mobil, truk, dan bus. Volume pejalan kaki yang menyeberang. Dan juga dimensi jalan seperti badan jalan, bahu jalan, meidan jalan dan juga trotar.

a. Volume kendaraan

Data jumlah kendaraan yang melintas dihitung setiap 15 menit sekali dengan menggunakan counter dan dibagi sesuai dengan jenis kendaraan (MC, LV, HV) pada puncak lalu lintas di pagi, siang, dan sore hari. Kemudian dicatat pada kertas form yang telah disiapkan.

b. Volume penyeberang jalan

Data jumlah pejalan kaki yang menyeberang pada lokasi yang akan dievaluasi dicatat setiap 15 menit menggunakan counter kemudia ditulis pada kertas form yang telah disiapkan.

c. Dimensi jalan

Badan, bahu jalan, dan juga trotoar diukur menggunakan roll meter pada waktu yang telah ditentukan.

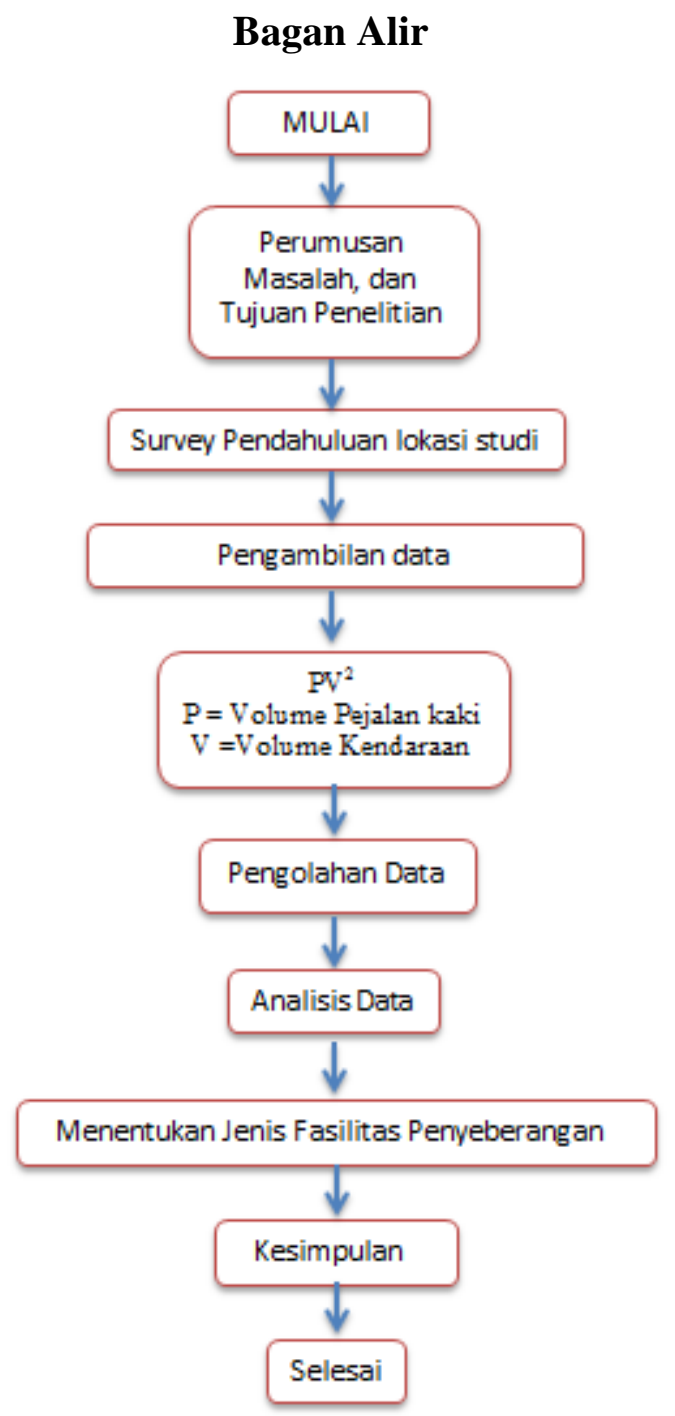

Gambar 5 Diagram Alir penelitian 


\section{ANALISIS DATA DAN PEMBAHASAN}

Dari hasil analisis pada data hasil pengamatan yang dilakukan pada hari senin, kamis, dan sabtu di lapangan didapatkan nilai total kendaraan dan penyeberang jalan dari dua arah dalam satu hari. Kemudian hasil dari ketiga hari tersebut dirata - rata dan didapatkan hasil dari perhitungan $\mathrm{PV}^{2}$ untuk menentukan jenis fasilitas penyeberangan.

Tabel 1 Rekapitulasi Arus Lalu Lintas

Kendaraan dan Penyeberang Jalan pada Jalan Teuku Umar Depan Pasar

\begin{tabular}{|c|c|c|c|c|c|}
\hline & & Jating & eh & & \\
\hline \multirow[b]{3}{*}{ Hari } & \multicolumn{2}{|c|}{ Total } & \multicolumn{2}{|c|}{ Rata-rata } & \multirow[b]{3}{*}{ PV2 } \\
\hline & $\begin{array}{c}\text { Smp/ } \\
\text { jam }\end{array}$ & $\begin{array}{c}\mathrm{Org} / \mathrm{ja} \\
\mathrm{m}\end{array}$ & V & $\mathrm{P}$ & \\
\hline & $\begin{array}{l}\text { dala } \\
\text { m } 1 \\
\text { hari }\end{array}$ & $\begin{array}{c}\text { dalam } 1 \\
\text { hari }\end{array}$ & $\begin{array}{l}\text { (smp } \\
\text { /jam) }\end{array}$ & $\begin{array}{c}\text { (or } \\
\mathrm{g} \\
\text { /ja } \\
\mathrm{m} \text { ) }\end{array}$ & \\
\hline Senin & $\begin{array}{c}5416, \\
93\end{array}$ & 51 & \multirow{3}{*}{$\begin{array}{c}4893 \\
, 13\end{array}$} & \multirow{3}{*}{$\begin{array}{l}45, \\
42\end{array}$} & \multirow{3}{*}{$\begin{array}{c}108739 \\
8217\end{array}$} \\
\hline Kamis & $\begin{array}{c}4889, \\
03 \\
\end{array}$ & 45,25 & & & \\
\hline Sabtu & $\begin{array}{c}4373, \\
44\end{array}$ & 40 & & & \\
\hline
\end{tabular}

(Sumber : Hasil Analisis Perhitungan)

Berdasarkan dari hasil perhitungan $\mathrm{PV}^{2}$ pada Jalan Teuku Umar depan Pasar Jatingaleh diperoleh nilai $10,87 \times 10^{8}$. Selanjutnya hasil tersebut dapat digunakan untuk menentukan jenis fasilitas penyeberangan sesuai dengan persyaratan pada tabel 2.4 dan tabel 2.5. Hasil perhitungan yang didapatkan yaitu $10,87 \times$ $10^{8}>2 \times 10^{8}$ dengan volume kendaraan (V) $>750 \mathrm{kend} / \mathrm{jam}$ dan volume pejalan kaki $(\mathrm{P})<50$ org/jam. hasil perhitungan tersebut belum memenuhi standar minimal yang ditetapkan untuk merancang fasilitas penyeberangan jalan. Akan tetapi pada saat pengamatan di lapangan terlihat bahwa pejalan kaki pada Pasar Jatingaleh sangat membutuhkan fasilitas penyeberangan karena arus lalu lintas kendaraan yang sangat padat sehingga penyeberang jalan membutuhkan waktu yang lama untuk menyeberang dan memperlambat pejalan kaki untuk melanjutkan aktifitas. Sehingga peneliti menyarankan untuk ruas jalan Teuku Umar pada titik lokasi Pasar Jatingaleh untuk direncanakan fasilitas penyeberangan tidak sebidang.

Tabel 2 Rekapitulasi Arus Lalu Lintas Kendaraan dan Penyeberang Jalan pada Jalan Teuku Umar Depan SMK Antonius

\begin{tabular}{|c|c|c|c|c|c|}
\hline \multirow{3}{*}{ Hari } & \multicolumn{2}{|c|}{ Total } & \multicolumn{2}{|c|}{ Rata-rata } & \multirow{3}{*}{ PV2 } \\
\hline & $\begin{array}{l}\text { Smp } \\
\text { /jam }\end{array}$ & $\begin{array}{l}\text { Org } \\
\text { /jam }\end{array}$ & V & $\mathrm{P}$ & \\
\hline & $\begin{array}{l}\text { dalam } \\
1 \text { hari }\end{array}$ & $\begin{array}{c}\text { dalam } 1 \\
\text { hari }\end{array}$ & $\begin{array}{l}\text { (smp } \\
\text { /jam) }\end{array}$ & $\begin{array}{c}\text { (or } \\
\mathrm{g} \\
\text { /ja } \\
\mathrm{m} \text { ) }\end{array}$ & \\
\hline Senin & $\begin{array}{c}4266, \\
69 \\
\end{array}$ & 1 & \multirow{3}{*}{$\begin{array}{c}3971, \\
47\end{array}$} & \multirow{3}{*}{$\begin{array}{c}0,5 \\
4\end{array}$} & \multirow{3}{*}{$\begin{array}{c}85434 \\
90\end{array}$} \\
\hline Kamis & $\begin{array}{c}4162, \\
38\end{array}$ & 0,5 & & & \\
\hline Sabtu & $\begin{array}{c}3485 \\
37\end{array}$ & 0,13 & & & \\
\hline
\end{tabular}

(Sumber : Hasil Analisis Perhitungan)

Berdasarkan hasil perhitungan $\mathrm{PV}^{2}$ pada Jalan Teuku Umar depan SMK Antonius diperoleh nilai $0,85 \times 10^{7}$. Selanjutnya hasil tersebut digunakan utnuk menentukan jenis fasilitas penyeberangan yang digunakan sesuai pada tabel 2.4 dan tabel 2.5. Hasil perhitungan yaitu $0,85 \times 10^{7}<2 \times$ $10^{8}$ dengan volume kendaraan $(\mathrm{V})>750$ kend/jam dan volume pejalan kaki $(\mathrm{P})<50$ org/jam. Dari hasil tersebut dapat disimpulkan bahwa pada ruas Jalan Teuku Umar depan SMK Antonius tidak memenuhi standar minimum yang 
ditetapkan pada tabel 2.4 dan tabel 2.5 untuk merancang fasilitas penyeberangan jalan. Pada titik lokasi SMK Antonius di Jalan Teuku Umar peneliti melihat bahwa ruas jalan tersebut sepi penyeberang sehingga peneliti menyarankan untuk titik lokasi tersebut tidak diperlukan fasilitas penyeberangan jalan.

Tabel 3 Rekapitulasi Arus Lalu Lintas

Kendaraan dan Penyeberang Jalan pada Jalan Pandanaran

\begin{tabular}{|c|c|c|c|c|c|}
\hline \multirow{2}{*}{ Hari } & \multicolumn{2}{|c|}{ Total } & \multicolumn{2}{c|}{ Rata-rata } & \multirow{2}{*}{ PV2 } \\
\cline { 2 - 5 } & $\begin{array}{c}\text { Smp } \\
\text { /jam }\end{array}$ & $\begin{array}{c}\text { Org } \\
\text { /jam }\end{array}$ & V & P & \multirow{2}{*}{ Palam } \\
\cline { 2 - 4 } & $\begin{array}{c}\text { dalam 1 } \\
\text { hari }\end{array}$ & $\begin{array}{c}\text { (smp } \\
\text { /jam) }\end{array}$ & $\begin{array}{c}\text { g } \\
\text { /ja } \\
\text { m) }\end{array}$ & \\
\hline Senin & $\begin{array}{c}2285, \\
01\end{array}$ & 31,88 & & & \\
\hline Kamis & $\begin{array}{c}2373, \\
44\end{array}$ & 28,00 & $\begin{array}{c}2349 \\
, 06\end{array}$ & $\begin{array}{c}25, \\
25\end{array}$ & $\begin{array}{c}13933 \\
137\end{array}$ \\
\hline Sabtu & $\begin{array}{c}2388, \\
74\end{array}$ & 15,88 & & & \\
\hline
\end{tabular}

(Sumber : Hasil Analisis Perhitungan)

Berdasarkan hasil perhitungan $\mathrm{PV}^{2}$ pada Jalan Pandanaran diperoleh nilai 1,39 $\times 10^{8}<2 \times 10^{8}$ dengan volume kendaraan (V) $>750 \mathrm{kend} / \mathrm{jam}$ dan volume pejalan kaki $(\mathrm{P})<50$ org/jam. Dari hasil perhitungan tersebut dapat disimpulkan bahwa untuk ruas Jalan Pandanaran tidak memenuhi standar minimum yang ditetapkan pada tabel 2.4 dan tabel 2.5 untuk merencanakan jenis fasilitas penyeberangan orang. Akan tetapi pada saat peneliti melakukan survey pada ruas jalan Pandanaran banyak pejalan kaki yang mencoba untuk menyeberang jalan dan terlihat kesulitan karena kecepatan kendaraan yang tinggi dan terdapat median berupa cone yang diikat dengan menggunakan tali tambang. Peneliti menyarankan untuk ruas jalan Pandanaran direncanakan fasilitas penyeberang jalan berupa pelican crossing (lampu swakelola).

Tabel 4 Rekapitulasi Arus Lalu Lintas

Kendaraan dan Penyeberang Jalan pada Jalan MT Haryono

\begin{tabular}{|c|c|c|c|c|c|}
\hline \multirow{3}{*}{ Hari } & \multicolumn{2}{|c|}{ Total } & \multicolumn{2}{|c|}{ Rata-rata } & \multirow{3}{*}{ PV2 } \\
\hline & $\begin{array}{l}\text { Smp } \\
\text { /jam }\end{array}$ & $\begin{array}{l}\text { Org } \\
\text { /jam }\end{array}$ & V & $\mathrm{P}$ & \\
\hline & $\begin{array}{l}\text { dala } \\
\mathrm{m} 1 \\
\text { hari }\end{array}$ & $\begin{array}{c}\text { dalam } 1 \\
\text { hari }\end{array}$ & $\begin{array}{c}\text { (smp } \\
\text { /jam } \\
\text { ) }\end{array}$ & $\begin{array}{c}\text { (or } \\
\mathrm{g} \\
/ \mathrm{ja} \\
\mathrm{m} \text { ) }\end{array}$ & \\
\hline Senin & $\begin{array}{c}1839 \\
, 84\end{array}$ & 50,88 & \multirow{3}{*}{$\begin{array}{c}1935 \\
, 57\end{array}$} & \multirow{3}{*}{$\begin{array}{l}59, \\
63\end{array}$} & \multirow{3}{*}{$\begin{array}{l}2233806 \\
73,26\end{array}$} \\
\hline Kamis & $\begin{array}{c}1891 \\
, 71\end{array}$ & 53,50 & & & \\
\hline Sabtu & $\begin{array}{c}2075 \\
, 16\end{array}$ & 74,50 & & & \\
\hline
\end{tabular}

(Sumber : Hasil Analisis Perhitungan)

Berdasarkan perhitungan $\mathrm{PV}^{2}$ tersebut pada Jalan MT Haryono yaitu $2,23 \times 10^{8}>2 \times 10^{8}$ dengan volume kendaraan $(\mathrm{V})>750 \mathrm{kend} / \mathrm{jam}$ dan volume pejalan kaki > 50 org/jam. Dari hasil tersebut dapat ditentukan jenis fasilitas penyeberangan orang pada Jalan MT Haryono yaitu pelican crossing (lampu swakelola) dengan lapak tunggu.

\section{Menentukan Durasi Lampu Lalu Lintas untuk Pelican crossing (lampu Swakelola)}

a. Durasi lampu lalu lintas untuk ruas jalan Pandanaran

Untuk nilai volume penyeberang jalan $(\mathrm{N})$ menggunakan periode yang memiliki jumlah penyeberang terbanyak dua arah yaitu 71 pada hari Senin pukul $15.30-17.30$.

$$
P T=\frac{L}{1,2}+1,7\left(\frac{N}{W-1}\right)
$$


$P T=\frac{18}{1,2}+1,7\left(\frac{71 / 120}{3-1}\right)$

$P T=15+1,7(0,295)$

$P T=15,502 \approx 16$ detik

Tabel 5 Periode Lampu Pelican Cross (lampu swakelola) pada Ruas Jalan Pandanaran

\begin{tabular}{|c|c|c|c|}
\hline \multirow{2}{*}{ Periode } & \multicolumn{2}{|c|}{ Lampu Untuk } & \multirow{2}{*}{$\begin{array}{l}\text { Durasi } \\
\text { (detik) }\end{array}$} \\
\hline & Kendaraan & $\begin{array}{c}\text { Pejalan } \\
\text { Kaki }\end{array}$ & \\
\hline 1 & Hijau & Merah & 7 \\
\hline 2 & Kuning & Merah & 3 \\
\hline 3 & Merah & Merah & 3 \\
\hline 4 & Merah & Hijau & 16 \\
\hline 5 & Merah & $\begin{array}{c}\text { Hijau } \\
\text { Berkedin }\end{array}$ & 3 \\
\hline 6 & Merah & Merah & 3 \\
\hline
\end{tabular}

(Sumber : Hasil Analisis Perhitungan)

b. Durasi lampu lalu lintas untuk ruas jalan MT Haryono

Untuk nilai volume penyeberang jalan $(\mathrm{N})$ menggunakan periode yang memiliki jumlah penyeberang terbanyak yaitu 162 pada hari Sabtu pukul $15.30-17.30$.

$$
\begin{aligned}
& P T=\frac{L}{1,2}+1,7\left(\frac{N}{W-1}\right) \\
& P T=\frac{18}{1,2}+1,7\left(\frac{162 / 120}{3-1}\right) \\
& P T=15+1,7(0,675) \\
& P T=16,1475 \approx 16 \text { detik }
\end{aligned}
$$

\begin{tabular}{|c|c|c|c|}
\hline \multirow{2}{*}{ Periode } & \multicolumn{2}{|c|}{ Lampu Untuk } & \multirow{2}{*}{$\begin{array}{l}\text { Durasi } \\
\text { (detik) }\end{array}$} \\
\hline & Kendaraan & $\begin{array}{c}\text { Pejalan } \\
\text { Kaki }\end{array}$ & \\
\hline 1 & Hijau & Merah & 7 \\
\hline 2 & Kuning & Merah & 3 \\
\hline 3 & Merah & Merah & 3 \\
\hline 4 & Merah & Hijau & 16 \\
\hline 5 & Merah & $\begin{array}{c}\text { Hijau } \\
\text { Berkedin }\end{array}$ & 3 \\
\hline 6 & Merah & Merah & 3 \\
\hline
\end{tabular}

Tabel 6 Periode Lampu Pelican Cross (lampu swakelola) pada Ruas Jalan MT

Haryono

(Sumber : Hasil Analisis Perhitungan)

\section{PENUTUP}

\subsection{Kesimpulan}

Pada hasil analisis dan hasil di lapangan yang telah ditinjau langsung oleh peneliti yaitu pada jalan Teuku Umar, Jalan Pandanaran, dan Jalan MT. Haryono dapat disimpulkan sebagai berikut :

a. Menurut pendapat peneliti saat melakukan penelitian pada ruas Jalan Teuku Umar (Pasar Jatingaleh) membutuhkan fasilitas penyeberang jalan karena hasil perhitungan PV2 yang diperoleh (yaitu 1.087.398.217) memenuhi syarat minimum (yaitu 200.000.000) untuk merencanakan fasilitas penyeberang jalan tidak sebidang.

b. Pada Jalan Teuku Umar (SMK Antonius) hubungan antara volume kendaraan dengan volume penyeberangan jalan masih tidak memenuhi persyaratan minimum. sangat sedikit apabila dibandingkan dengan titik lokasi Pasar Jatingaleh. Sehingga sesuai dengan hasil perhitungan dan penelitian di lapangan 
untuk titik lokasi ini tidak diperlukan fasilitas penyeberangan orang.

c. Pada Jalan Pandanaran hubungan antara volume kendaraan dengan volume penyeberang jalan masih tidak memenuhi persyaratan minimum. Namun menurut pendapat peneliti untuk ruas jalan ini membutuhkan fasilitas penyeberang jalan berupa pelican cross (lampu swakelola). Karena pada ruas ini hasil perhitungan PV2 (yaitu 139.332.136,5) nilai ini melebihi (100.000.000) syarat minimum untuk merencanakan fasilitas penyeberangan pelican crossing (lampu swakelola).

d. Pada Jalan MT Haryono hubungan antara volume kendaraan dengan volume penyeberang jalan sudah memenuhi persyaratan minimum pada tabel 2.4 dan tabel 2.5. Nilai perhitungan PV2 pada ruas jalan ini (yaitu 223.380.673,3) sudah memenuhi syarat minimum (yaitu 200.000.000). Fasilitas penyeberang orang yang disarankan pada ruas jalan ini yaitu pelican crossing (lampu swakelola) dengan lapak tunggu.

e. Hasil analisa untuk menentukan durasi dari lampu pelican crossing (lampu swakelola) untuk kedua ruas Jalan Pandanaran dan MT Haryono didapatkan durasi lampu hijau untuk pejalan kaki menyeberang selama 16 detik.

\subsection{Saran}

Berdasarkan hasil analisis dan pengamatan yang telah dilakukan, peneliti menyarankan sebagai berikut :

a. Melihat kondisi lapangan pada jalan Teuku Umar pada titik lokasi Pasar Jatingaleh, diperlukan pembangunan fasilitas penyeberangan jalan untuk pejalan kaki. Karena volume dan kecepatan kendaraan yang tinggi mengancam keselamatan pejalan kaki. Hal ini mengakibatkan para pejalan kaki merasa kurang aman dan nyaman pada saat menyeberang. Peneliti menyarankan untuk titik lokasi ini agar dibangun fasilitas penyeberangan tidak sebidang (berupa jembatan penyeberangan atau underpass (terowongan).

b. Pada ruas jalan MT Haryono menurut analisa perhitungan pada titik lokasi tersebut diperlukan fasilitas penyeberangan berupa pelican cross (lampu swakelola). Akan tetapi pelican cross (lampu swakelola) dapat menyebabkan kepadatan lalu lintas ketika lampu pelican cross (lampu swakelola) beroperasi saat pejalan kaki menyeberang. Kendaraan dari arah tanah putih menuju java mall akan menumpuk dan mengalami kepadatan yang akan mengganggu lalu lintas kendaraan dari arah pasar kambing maupun dari arah tanah putih. Dan juga dari arah peterongan menuju java mall kendaraan akan menumpuk dan mengganggu lalu lintas kendaraan dari arah sriwijaya menuju jalan MT Haryono. Oleh karena itu peneliti menyarankan pada titik lokasi ini untuk dibangun jenis fasilitas penyeberangan tidak sebidang berupa jembatan penyeberangan atau underpass (terowongan).

c. Sebaiknya pemerintah lebih mengutamakan keselamatan dan kenyamanan pengguna fasilitas umum yang lebih ramah lingkungan dan mengurangi volume kendaraan.

\section{DAFTAR PUSTAKA}

Asnanti, Fransiska R. 2017. Perancangan Kebutuhan Jembatan Penyeberangan 
Orang (Jpo) Berdasarkan Analisis Hubungan Arus KendaraanPenyeberang Jalan Dan Perilaku Lalu Lintas (Studi Kasus : Jalan Persatuan, Yogyakarta). Laporan Tugas Akhir Atma Jaya Yogyakarta Program Studi Teknik Sipil. Yogyakarta.

Fish, Richard. 2005. Planning, Transportation \& Estates Traffic Engineering Manual 4 Pedestrian Crossing. United Kingdom: Cornwall County Council. (e-book)

Jain, Udit, dan Rajat Rastogi. 2016. World Conference on Transport Research WCTR 2016 Shanghai. ReExamination of PV2 Criteria for Developing Pedestrian Crossing Warrants, 1717(8). Retrieved from https://www.researchgate.net/publicat ion/317423974_Re-

Examination_of_PV_2_Criteria_for_ Developing_Pedestrian_Crossing_W arrants.

Tanan, Natalia. 2012. Kajian Celah Yang Diperlukan untuk menentukan fasilitas penyeberangan pejalan kaki (Study on gap acceptance to dtermine pedestrian crossing fasilities). Laporan Tugas Akhir

Tanan, Natalia. 2017. Pedoman Bahan Konstruksi Bangunana dan Rekayasa Sipil. Perencanaan Teknis Fasilitas Pejalan Kaki. Jurnal Kementerian Pekerjaan Umum dan Perumahan Rakyat.

Priastama, Pungkas. 2015. Analisis Dan Perancangan Kebutuhan Jembatan Penyeberangan Orang (Studi Kasus Jalan Diponegoro dan Jalan Laksda. Adisutjipto Yogyakarta). Laporan Tugas Akhir Universitas Atma Jaya
Yogyakarta Program Studi Teknik Sipil. Yogyakarta.

Sahari, Wira, dan Slamet Widodo. 2016. Kajian Kebutuhan Fasilitas Penyeberangan Pada Ruas Jalan Di Area Komersial Kota Pontianak (Studi Kasus: Jl Teuku Umar - Jl. Hos Cokroaminoto, Kota Pontianak) Jurnal Mahasiswa Teknik Sipil Universitas Tanjungpura

Siswanto, Joko, dan Julianto Teguh. 2008. Analisis Kebutuhan Jenis Fasilitas Penyeberangan Jalan Berdasarkan Gap Kritis (Studi Kasus PT. Sido Muncul Ungaran - Jawa Tengah). Tim Pengajar Fakultas Teknik Jurusan Sipil Universitas Diponegoro. Semarang.

Wicaksono, Y.I, dan Joko Siswanto. 2011. Kebutuhan Fasilitas Penyeberangan Jalan Dengan Metode Gap Kritis (Studi Kasus Jalan Raya Semarang Kendal Km 16.50). Staf Pengajar Jurusan Teknik Sipil Fakultas Teknik Universitas Diponegoro. 